\title{
Competição esportiva na infância: análise dos regulamentos de ginástica rítmica
}

\section{RESUMO}

Pautando-se nos princípios do Modelo de Participação Competitiva e Engenharia Competitiva, que consideram as competições como parte do processo da aprendizagem esportiva que visa o desenvolvimento positivo de jovens, analisamos o cenário competitivo para os primeiros anos da ginástica rítmica. Para tanto, realizamos uma análise documental dos regulamentos de competições brasileiras de ginástica rítmica da categoria mirim. Por meio da Análise de Conteúdo, identificamos, essencialmente: a. rotina de apresentação sem o uso de equipamento de pequeno porte; $b$. permissão para uso de uniforme de equipe e/ou fantasia na performance; c. diminuição do espaço a ser explorado pela ginasta; c. consideráveis ajustes nos quesitos dificuldade e execução de elementos; d. variáveis modelos de premiação; e. ampliação no número de eventos e, consequentemente, na experiência competitiva das atletas mirins. Os resultados indicam coerência entre os eventos e teóricos da área e fomentam a modalidade por meio do incentivo à participação.

PALAVRAS-CHAVE: Ginástica; Atletas; Educação física e treinamento

\section{Lorena Nabanete dos Reis-Furtado}

Mestre

Universidade Federal do Ceará - UFC Instituto de Educação Física e Esportes Fortaleza, Ceará, Brasil lorenareis@gmail.com

https://orcid.org/0000-0001-6593-4646

Michele Viviene Carbinatto

Doutora

Universidade de São Paulo - USP

Escola de Educação Física e Esporte

São Paulo, São Paulo, Brasil mcarbinatto@usp.br

https://orcid.org/0000-0001-6598-9938 


\title{
Sport competition: analisys into novice rhythmic gymnastics events rules
}

\begin{abstract}
Considering the principles of the Competitive Sport Participation and Competitive Engineering, which recognize competition as part of the process of learning in sports, that aims the positive development of youth athlete, we analyze the competition scenario for the formative Rhythmic Gymnastics years. A documentary analysis of the rules of Brazilian competition in RG for child under eight years old was carried out. Through Content Analysis, it was identified: a. routine performance without hand apparatus; b. permission to be dressed with team uniform and/or costume; c. considerable adjustments in difficulty and execution of elements; d. variable award models; and e. increased number of events, consequently, in the competitive experience for the novice athletes. The results indicate coherence between the events and theory and encourage RG novice athlete participation.
\end{abstract}

KEYWORDS: Gymnastics; Athletes; Physical education and training

\section{Competencia deportiva en la infância: análisis de reglas de eventos de gimnasia rítmica}

\section{RESUMEN}

Con base en los principios del Modelo de Participación Competitiva y la Ingeniería Competitiva, que consideran las competiciones deportivas como parte del proceso de aprendizaje de uno deporte que apunta al desarrollo positivo de los jóvenes, analizamos el escenario competitivo para los primeros años de gimnasia rítmica. Con este fin, se realizó un Análisis Documental de las regulaciones de las competiciones brasileñas en GR de la categoría menor de ocho años. A través del Análisis de Contenido, se identificó, esencialmente: a. rutina de presentación sin el uso de aparatos; permiso para usar uniforme del equipo y/o trajes de fantasías; c. disminución en el espacio a ser explorado por la gimnasta; d. Modelos de premios variables; e. expansión en el número de eventos y, en consecuencia, en la experiencia competitiva de los pequeños atletas. Los resultados indican coherencia entre los eventos y los teóricos en el área y alientan la participación de la RG.

PALABRAS-CLAVE: Gimnasia; Atletas; Educación y entrenamiento físico 


\section{INTRODUÇÃO}

A competição esportiva para crianças e jovens têm sido tema de estudos na área da Pedagogia do Esporte, em diferentes modalidades, isso porque ela é inerente ao processo de formação esportiva do atleta, sendo considerada a essência do esporte (BENTO, 2006; CRANE; TEMPLE, 2015). Aprender a competir faz parte do processo de aprendizagem do próprio contexto esportivo (MONTAGNER; SCAGLIA; 2013), sendo o ambiente competitivo rico em situações que podem fortalecer o desenvolvimento social, moral e ético para a vida (LEONARDO; GALATTI; SCAGLIA, 2017).

Apesar disso, esse não é um processo tão óbvio. O valor educativo da participação em competições depende da forma como os atletas são conduzidos, assim como das experiências vividas nesse contexto (NISTA-PÍCOLLO; NUNOMURA, 2014). O que temos observado é que o ambiente competitivo destinado aos jovens atletas tem sido muito semelhante ao dos adultos, no que diz respeito ao sistema, expectativas e objetivos e se torna não apropriado, pois estimula a especialização precoce, o que leva a uma competição também precoce, com ênfase nos resultados a serem alcançados (BOMPA, 2000; MARQUES, 2003).

$\mathrm{Na}$ prática, tem ocorrido um tratamento desproporcional com o que se espera de uma formação voltada para os valores educacionais do esporte, com jovens atletas sendo treinados para campeonatos mirins e infantis como se dependessem dessas vitórias para o sucesso futuro (CAFRUNI, MARQUES e GAYA, 2006). Ademais, considerando o diferente nível de maturação de jovens atletas, mesmo dos que tenham idades próximas, o desenvolvimento do talento esportivo não necessariamente é associado aos resultados conquistados nos anos iniciais da prática (LEONARDO; GALATTI; SCAGLIA, 2017). Dessa forma, o caráter formativo do esporte se anula, pois, os treinos passam a ser orientados pelas demandas da competição e não pela formação do sujeito.

Logo, a competição para crianças e jovens é um aspecto extremamente importante do processo de formação esportiva e pode contribuir para a vida do indivíduo como um todo, desde que seja organizada de acordo com as necessidades, motivações e interesses dos praticantes em cada época de sua carreira esportiva (MARQUES, 2003). Para isso, as competições devem assumir diferentes formatos no processo de formação esportiva, de acordo com a transição da carreira, passando pelas competições não formais ou festivais e percorrendo uma progressão gradual até chegar à competição formal e institucionalizada, de forma a levar os atletas a compreenderem seu real sentido e aprimorarem sua participação em todos os níveis. 
Nesse sentido, a Engenharia Competitiva (EC) (BURTON, GILLHAM; HAMMERMEISTER, 2011) é uma estrutura teórica que propõe mudanças nas competições, que promovam experiências competitivas positivas com objetivo prioritário de buscar o maior envolvimento do atleta e estimular a motivação intrínseca. Para isso, procura alcançar algumas metas que trarão esse engajamento, por meio de alterações estruturais, materiais, das instalações esportivas e das regras do jogo, promovendo um estímulo à participação, por meio de um ambiente ajustado aos interesses e nível de desenvolvimento das crianças.

São as chamadas Metas de Engajamento de Atleta: 1. Aumentar a ação e pontuação procura que o atleta esteja mais ativo durante o jogo, aumentando a pontuação da equipe/atleta no mesmo. Para isso, diminuir tamanho do espaço ou modificar tamanho e peso dos equipamentos são estratégias recomendadas; 2. Criar alto envolvimento pessoal - objetiva incentivar autonomia e engajamento na atividade. Estratégias voltadas para que os atletas contribuam significativamente para o sucesso da equipe e estimulem sensação de pertencimento e envolvimento com as tarefas são as mais indicadas; 3. Manter pontuações próximas - propõe evitar discrepância entre os resultados, para que não haja perda de motivação e prazer, pela sensação de falta de competência. É sugerido que a organização do evento equalize os níveis da competição e crie regras para que os resultados não sejam tão distantes; 4. Promover relações sociais positivas - criar práticas que envolvam as diferentes equipes e regras de socialização entre os atletas, a fim de criar um ambiente social mais positivo e promover a chance dos atletas compartilharem momentos fora do ambiente de competição (BURTON, GILLHAM; HAMMERMEISTER, 2011).

Esses ajustes são voltados para jovens que estão nos primeiros estágios de sua formação esportiva - anos de experimentação e anos de especialização - do Modelo de Desenvolvimento da Participação Desportiva (MDPD) (CÔTÉ, 1999; CÔTÉ; STRACHAN; FRASER-THOMAS, 2008; CÔTÉ; HAY, 2002). Além da EC, o Sistema de Classificação para Programas Esportivos (WIERSMA, 2005), surgiu com intuito de trazer uma classificação (do nível 1 ao 4) que trouxesse informações sobre a adequação dos objetivos dos eventos, de forma a atender às demandas de habilidade e maturidade competitiva dos participantes. Estudos sobre formação de atletas e competições para crianças e jovens utilizando essas bases teóricas já foram desenvolvidos no Brasil, em modalidades como voleibol (MENDES, 2017) e handebol (LEONARDO; SCAGLIA, 2018; LEONARDO; SCAGLIA, 2018a; LEONARDO; SCAGLIA, 2018b), haja vista que tais modelos são voltados principalmente para as características dos esportes coletivos.

A ginástica rítmica apresenta características distintas dessas. Tomando como base a Teoria da Praxiologia Motriz de Parlebas (2001), os esportes coletivos são caracterizados como uma prática sociomotriz de cooperação e oposição (LANES et. al, 2018), quando se tem 
simultaneamente adversários e companheiros atuando e se relacionando de forma direta; enquanto a ginástica rítmica, em sua prova individual assume o caráter de prática psicomotriz - ausência de companheiros e adversários diretos na ação do "jogo"; e na prova de conjunto, caráter sociomotriz de cooperação - presença de companheiros e/ou adversários que se relacionam de forma direta (MENEGALDO; BORTOLETO, 2018). Dessa maneira, são esportes que assumem uma lógica interna diferenciada e, portanto, possuem características de treinamento e competições também diversas.

Além disso, a GR, assim como outros esportes artísticos como a ginástica artística e a patinação artística, tende a ter o início da fase de especialização mais precoce do que em outros esportes (BALYI, 2001; ARENA; BOHME, 2004; LAW; CÔTÉ; ERICSSON, 2007; NUNOMURA; CARRARA; TSUKAMOTO, 2010), sendo a primeira etapa da formação esportiva - a iniciação - compreendida entre seis e oito anos de idade. Aos nove anos de idade, as ginastas já podem participar de competições oficiais na categoria pré-infantil, nacional e internacionalmente.

Apesar dessas distinções, notamos que também na ginástica rítmica e em outras ginásticas esportivas, existe atualmente uma preocupação com a formação dos ginastas em longo prazo, com modelos fundamentados em aspectos semelhantes aos encontrados nos modelos de formação dos esportes coletivos.

$\mathrm{Na}$ GR alguns programas com base na formação de atletas em longo prazo têm sido desenvolvidos, como é o caso do Programa “Age Group” da Federação Internacional de Ginástica (FIG), que propõe o desenvolvimento de um programa completo de treinamento e de competições que pode ser utilizado pelas federações nacionais de ginástica, no caso de não haver um programa próprio (FIG, 2018); além de outros modelos desenvolvidos pelas federações nacionais, como por exemplo, o Long Term Athlete Development (LTAD) da Federação Canadense de Ginástica (GYMNASTICS CANADA GYMNASTIQUE, 2008); e o programa de competições da Federação de Ginástica dos Estados Unidos (USAGYM, 2019), que prevê a divisão de níveis competitivos até se alcançar a excelência. Todos eles apresentam características comuns aos modelos propostos para outras modalidades, porém adaptando às especificidades da ginástica.

O Brasil ainda não desenvolveu um programa específico de formação de ginastas em longo prazo, porém já observamos que há uma preocupação da Confederação Brasileira de Ginástica (CBG) em ajustar os regulamentos dos eventos das categorias menores, aproximando-os das orientações da CONSUGI - Confederação Sul-americana de Ginástica - que, por sua vez, busca se orientar pelo programa Age Group da FIG. Porém, esses eventos são voltados para categorias a partir do pré-infantil (09 e 10 anos), deixando a cargo das federações estaduais, ligas e clubes, a organização de eventos para idades menores do que essa categoria. 
Tomando como base os princípios teóricos de uma formação de atleta em longo prazo, que considere as competições como parte do processo de aprendizagem esportiva visando ao desenvolvimento positivo de jovens (CÔTÉ, 1999; CÔTÉ; HAY, 2002; WIERSMA, 2005; CÔTÉ; STRACHAN; FRASER-THOMAS, 2008), procuramos compreender o cenário competitivo atual para os primeiros anos na ginástica rítmica, frente às necessidades do desenvolvimento das crianças participantes, bem como da modalidade. Para isso nos apoiamos também no Modelo de Participação Competitiva (LEONARDO; GALATTI; SCAGLIA, 2017), que considera necessária a transformação da competição de jovens, buscando diminuir a evasão e aumentar o interesse, por meio da equalização de oportunidades de competir, favorecendo assim, maior oportunidade de aprendizado por meio da competição. Nesse modelo, a Engenharia Competitiva (BURTON, GILLHAM; HAMMERMEISTER, 2011) e o Sistema de Classificação para Programas Esportivos (WIERSMA, 2005) são utilizados para repensar as competições para jovens atletas.

A partir desse cenário, a presente pesquisa teve como objetivo analisar os regulamentos das competições de ginástica rítmica voltadas para a categoria mirim, promovidas por federações estaduais de ginástica do Brasil.

\section{MÉTODOS}

\section{Natureza da pesquisa}

O estudo, de natureza qualitativa, foi realizado por meio de uma pesquisa documental a partir de regulamentos de competições de ginástica rítmica para categoria mirim, realizadas por três federações estaduais de ginástica. A característica de uma pesquisa documental é utilizar como fonte de coleta de dados, documentos que constituem as chamadas fontes primárias, que podem ter sido feitas no momento em que o fato/fenômeno ocorre, ou depois (MARCONI; LAKATOS, 2003).

A pesquisa documental é ainda constituída como o exame detalhado de diferentes materiais, que permite interpretações novas e/ou complementares sobre os mesmos. Dessa maneira, os documentos constituem uma fonte não reativa e, portanto, sem perigo de alteração mesmo com o passar do tempo; além disso, o documento é uma fonte natural de informação, por ter origem em determinado contexto e fornecer dados sobre o mesmo (GODOY, 1995).

\section{Critérios para a definição da amostra}

Considerando que o início das competições oficiais promovidas pela CBG se dá aos nove anos de idade (categoria pré-infantil), foram analisados os resultados dos campeonatos brasileiros de individual, bem como dos campeonatos brasileiros de conjunto dessa categoria, realizados entre 
2013 e 2019. A análise foi feita com base nos resultados oficiais disponíveis no site oficial da Confederação Brasileira de Ginástica $(\mathrm{CBG})$ e indicou as equipes medalhistas na prova por equipe dos campeonatos individuais e na classificação geral dos campeonatos de conjunto. Para que a equipe fosse incluída no critério, a mesma deveria estar entre as medalhistas em pelo menos dois anos, em qualquer um dos eventos, apresentando assim, critério de consistência nos resultados obtidos no período.

Pressupomos que os resultados reflitam o trabalho de preparação das instituições para que as ginastas iniciem suas participações em competições oficiais, considerando não somente os resultados dos talentos individuais. Além disso, entendemos que os bons resultados da equipe na categoria pré-infantil indicam que houve um processo satisfatório de transição entre o ambiente da prática da iniciação e a inserção nos ambientes competitivos, o que inclui no processo a participação nos eventos promovidos pelas federações estaduais.

Dessa forma, chegamos a seis equipes, que são filiadas a três federações estaduais. Nesse sentido foram analisados os regulamentos de seis competições dessas federações, em que figuram a categoria mirim ( 7 a 8 anos de idade) do ano de 2019, bem como os calendários de eventos dessas entidades para o mesmo ano.

\section{Coleta e análise dos dados}

Os regulamentos dos eventos foram coletados por meio de consulta e download dos sites e redes sociais oficiais das federações incluídas no estudo.

Inicialmente, todos os regulamentos dos eventos das três instituições passaram por uma préanálise para identificar quais se enquadravam na idade/categoria selecionada para o estudo. Em seguida, realizamos a Análise de Conteúdo (BARDIN, 2011), com foco nas modificações efetuadas nos regulamentos para a categoria mirim, em comparação aos eventos oficiais da modalidade, regidos pelo Código de Pontuação de Ginástica Rítmica da Federação Internacional de Ginástica e voltadas para a categoria adulta.

\section{Procedimentos éticos}

Este estudo faz parte de um projeto de pesquisa maior, aprovado pelo parecer $\mathrm{n}^{\circ} 1.993 .995$ do Comitê de Ética em Pesquisa da Universidade de São Paulo. 


\section{RESULTADOS}

A partir da análise de conteúdo dos regulamentos selecionados, identificamos cinco categorias que representam os aspectos relacionados aos ajustes previstos para as competições, quando comparados aos eventos oficiais para a categoria adulta (Quadros 1, 2, 3, 4 e 5): 1. Ajustes na estrutura física e materiais; 2. Ajustes das regras; 3 . Ajustes no julgamento; 4. Ajustes na forma da premiação; 5. Localização e quantidade de eventos.

Cada quadro contém o tipo de ajuste proposto no regulamento, em quais e quantos eventos esse tipo de alteração aparece, um exemplo de unidade de significado, a estratégia para implementação da Engenharia Competitiva, assim como a respectiva meta de engajamento do atleta alcançada por meio dessa modificação.

Quadro 1 - Ajustes na estrutura física e materiais

\begin{tabular}{|c|c|c|c|c|c|}
\hline $\begin{array}{l}\text { Tipos de } \\
\text { ajustes }\end{array}$ & $\begin{array}{c}\text { Evento } \\
\text { s }\end{array}$ & $\%$ & Unidades de significado & $\begin{array}{c}\text { Estratégia - } \\
\text { EC }\end{array}$ & $\begin{array}{c}\text { Meta de } \\
\text { Engajamento } \\
\text { alcançada } \\
\end{array}$ \\
\hline $\begin{array}{l}\text { a. alteração } \\
\text { do espaço }\end{array}$ & $\begin{array}{l}\text { E2, E3, } \\
\text { E4, E6 }\end{array}$ & & $\begin{array}{l}\text { "as séries serão realizadas } \\
\text { em um retângulo de } 13 \times 5 m^{\prime}\end{array}$ & $\begin{array}{l}\text { modificar } \\
\text { instalações }\end{array}$ & $\begin{array}{l}\text { aumentar ação } \\
\text { e pontuação }\end{array}$ \\
\hline $\begin{array}{l}\text { b. prova } \\
\text { sem } \\
\text { aparelhos }\end{array}$ & $\begin{array}{l}\text { E1, E2, } \\
\text { E3, E4, } \\
\text { E5, E6 }\end{array}$ & 0 & "Provas: mãos livres" & equipamento & $\begin{array}{c}\text { aumentar ação } \\
\text { e pontuação }\end{array}$ \\
\hline $\begin{array}{l}\text { c. uso de } \\
\text { fantasias }\end{array}$ & E1, E3 & & $\begin{array}{c}\text { "a criança deverá } \\
\text { preferencialmente competir } \\
\text { caracterizada com o } \\
\text { personagem de sua } \\
\text { coreografia (fantasia)" }\end{array}$ & equipamento & $\begin{array}{c}\text { criar alto } \\
\text { envolvimento } \\
\text { pessoal }\end{array}$ \\
\hline $\begin{array}{l}\text { d. uso de } \\
\text { uniforme de } \\
\text { treino }\end{array}$ & E2 & & $\begin{array}{c}\text { "as meninas deverão estar } \\
\text { vestidas com o uniforme da } \\
\text { equipe" }\end{array}$ & equipamento & $\begin{array}{l}\text { Não } \\
\text { relacionado às } \\
\text { metas - menor } \\
\text { custo para } \\
\text { participação }\end{array}$ \\
\hline
\end{tabular}

Quadro 2 - Ajustes das regras técnicas dos eventos

\begin{tabular}{|c|c|c|c|c|c|}
\hline $\begin{array}{c}\text { Tipos de } \\
\text { ajustes }\end{array}$ & $\begin{array}{c}\text { Evento } \\
\text { s }\end{array}$ & $\mathbf{\%}$ & Unidades de significado & $\begin{array}{c}\text { Estratégia - } \\
\text { EC }\end{array}$ & $\begin{array}{c}\text { Meta de } \\
\text { Engajamento } \\
\text { alcançada }\end{array}$ \\
\hline $\begin{array}{c}\text { a. número } \\
\text { de ginastas } \\
\text { - conjunto }\end{array}$ & E1, E6 & 33 & $\begin{array}{c}\text { "Cada conjunto poderá ser } \\
\text { composto por no minimo 2 e } \\
\text { máximo 5 ginastas" }\end{array}$ & regra & $\begin{array}{c}\text { criar alto } \\
\text { envolvimento } \\
\text { pessoal }\end{array}$ \\
\hline $\begin{array}{c}\text { b. } \\
\text { apresentaçã } \\
\text { o única }\end{array}$ & $\begin{array}{c}\text { E1, E2, } \\
\text { E5, E4, E6 }\end{array}$ & 10 & $\begin{array}{c}\text { "Haverá apenas uma } \\
\text { apresentação que } \\
\text { Eeterminará o individual por } \\
\text { aparelho" }\end{array}$ & regra & $\begin{array}{c}\text { NRD - menor } \\
\text { tempo de } \\
\text { evento, menor } \\
\text { custo }\end{array}$ \\
\hline $\begin{array}{c}\text { c. } \\
\text { elementos }\end{array}$ & E1 & 15 & $\begin{array}{c}\text { *Regulamento apresenta } \\
\text { tabela com nome, símbolo, }\end{array}$ & regra & $\begin{array}{c}\text { manter } \\
\text { pontuações }\end{array}$ \\
\hline
\end{tabular}




\begin{tabular}{|c|c|c|c|c|c|}
\hline obrigatórios & & & $\begin{array}{c}\text { valor e critérios de execução } \\
\text { do elemento }\end{array}$ & & próximas \\
\hline $\begin{array}{c}\mathrm{d} . \\
\text { elementos e } \\
\text { música } \\
\text { obrigatórios }\end{array}$ & E2, E6 & 33 & $\begin{array}{l}\text { *Regulamentos apresentam } \\
\text { tabela com nome, símbolo, } \\
\text { valor e critérios de execução } \\
\text { do elemento e indicam } \\
\text { música para a composição }\end{array}$ & regra & $\begin{array}{c}\text { manter } \\
\text { pontuações } \\
\text { próximas }\end{array}$ \\
\hline $\begin{array}{c}\text { e. série } \\
\text { obrigatória }\end{array}$ & E4 & 16 & $\begin{array}{c}\text { *Existe uma descrição } \\
\text { completa dos exercícios e da } \\
\text { sequência no espaço que } \\
\text { deverá ser realizada pelas } \\
\text { ginastas na música } \\
\text { determinada pela organização }\end{array}$ & regra & $\begin{array}{c}\text { manter } \\
\text { pontuações } \\
\text { próximas }\end{array}$ \\
\hline $\begin{array}{l}\text { f. valor } \\
\text { máximo } \\
\text { e/ou } \\
\text { quantidade } \\
\text { de } \\
\text { dificuldade } \\
\text { limitados }\end{array}$ & $\begin{array}{l}\text { E1, E2, } \\
\text { E3, E4, } \\
\text { E5, E6 }\end{array}$ & $\begin{array}{c}10 \\
0\end{array}$ & $\begin{array}{c}\text { "Dificuldade: valor máximo } \\
\text { de } 1,30 "\end{array}$ & regra & $\begin{array}{c}\text { manter } \\
\text { pontuações } \\
\text { próximas }\end{array}$ \\
\hline $\begin{array}{l}\text { g. tempo do } \\
\text { exercício } \\
\text { reduzido }\end{array}$ & E3, E6 & 33 & "Duração: de 50" a 1"" & regra & $\begin{array}{c}\text { Não } \\
\text { relacionado às } \\
\text { metas }\end{array}$ \\
\hline
\end{tabular}

Quadro 3 - Ajustes realizados na forma do julgamento dos eventos, em relação ao Código de Pontuação de Ginástica Rítmica da FIG.

\begin{tabular}{|c|c|c|c|c|c|}
\hline $\begin{array}{l}\text { Tipos de } \\
\text { ajustes }\end{array}$ & $\begin{array}{c}\text { Evento } \\
\mathrm{s}\end{array}$ & $\%$ & Unidades de Significado & $\begin{array}{c}\text { Estratégia - } \\
\text { EC }\end{array}$ & $\begin{array}{c}\text { Meta de } \\
\text { Engajamento } \\
\text { alcançada }\end{array}$ \\
\hline $\begin{array}{l}\text { a. valores } \\
\text { de BD } \\
\text { alterados }\end{array}$ & E1, E2 & $\begin{array}{l}33 \\
\%\end{array}$ & $\begin{array}{l}* \text { Regulamento apresenta } \\
\text { tabela com todos os } \\
\text { elementos obrigatórios com } \\
\text { valor único de } 0,30\end{array}$ & regra & $\begin{array}{l}\text { manter } \\
\text { pontuações } \\
\text { próximas }\end{array}$ \\
\hline $\begin{array}{c}\text { b. } \\
\text { diminuiçãa/ } \\
\text { alteração } \\
\text { dos valores } \\
\text { das faltas } \\
\text { técnicas e } \\
\text { artísticas } \\
\end{array}$ & $\begin{array}{c}\text { E1, E2, } \\
\text { E3 }\end{array}$ & $\begin{array}{l}50 \\
\%\end{array}$ & $\begin{array}{c}\text { "as deduções da execução e } \\
\text { de artístico serão as } \\
\text { seguintes e serão deduzidas } \\
\text { da nota máxima de } 10 \\
\text { pontos: falta pequena-0,10, } \\
\text { falta média-0,20, falta grave- } \\
0,30 \text { " }\end{array}$ & regra & $\begin{array}{l}\text { manter } \\
\text { pontuações } \\
\text { próximas }\end{array}$ \\
\hline $\begin{array}{l}\text { c. validação } \\
\text { de BD, } \\
\text { mesmo } \\
\text { com erros }\end{array}$ & E1, E2 & $\begin{array}{l}33 \\
\%\end{array}$ & $\begin{array}{c}\text { "um elemento é validado } \\
\text { mesmo que seja executado } \\
\text { com erros, a menos que os } \\
\text { erros sejam graves ao ponto } \\
\text { de modificarem a } \\
\text { característica do elemento" }\end{array}$ & regra & $\begin{array}{l}\text { manter } \\
\text { pontuações } \\
\text { próximas }\end{array}$ \\
\hline $\begin{array}{c}\text { d. } \\
\text { quantidade } \\
\text { de árbitros }\end{array}$ & $\mathrm{E} 1, \mathrm{E} 2$ & $\begin{array}{l}33 \\
\%\end{array}$ & $\begin{array}{l}\text { "Cada árbitro irá pontuar a } \\
\text { dificuldade e a execução" }\end{array}$ & regra & $\begin{array}{c}\text { Não } \\
\text { relacionado às } \\
\text { metas - menor } \\
\text { custo } \\
\end{array}$ \\
\hline
\end{tabular}




\begin{tabular}{|c|c|c|c|c|c|}
\hline $\begin{array}{c}\text { e. somente } \\
\text { execução } \\
\text { técnica é } \\
\text { avaliada }\end{array}$ & E4, E6 & $\begin{array}{c}33 \\
\%\end{array}$ & $\begin{array}{c}\text { "Penalidade: 0,20 se deixar } \\
\text { de realizar algum elemento } \\
\text { obrigatório - Execução: de } \\
\text { zero à 10,00 pontos" }\end{array}$ & regra & $\begin{array}{c}\text { manter } \\
\text { pontuações } \\
\text { próximas }\end{array}$ \\
\hline
\end{tabular}

Quadro 4 - Ajustes na forma de premiação dos eventos

\begin{tabular}{|c|c|c|c|c|c|}
\hline $\begin{array}{l}\text { Tipos de } \\
\text { ajustes }\end{array}$ & Eventos & $\%$ & Unidades de significado & $\begin{array}{c}\text { Estratégia - } \\
\text { EC }\end{array}$ & $\begin{array}{c}\text { Meta de } \\
\text { Engajamento } \\
\text { alcançada } \\
\end{array}$ \\
\hline $\begin{array}{l}\text { a. medalhas } \\
\text { de } \\
\text { participação } \\
\text { para todas/ } \\
\text { evento sem } \\
\text { classificação }\end{array}$ & E6 & $16 \%$ & $\begin{array}{l}\text { "Todas as ginastas } \\
\text { receberão medalha de } \\
\text { participação" }\end{array}$ & regra & $\begin{array}{l}\text { Criar alto } \\
\text { envolvimento } \\
\text { pessoal }\end{array}$ \\
\hline $\begin{array}{c}\text { b. } \\
\text { premiação } \\
\text { do } 1^{\circ} \text { ao } 10^{\circ} \% \\
6^{\circ} \text { lugar } / 20 \% \\
+ \text { medalhas } \\
\text { de } \\
\text { participação }\end{array}$ & $\begin{array}{l}\text { E3, E4, } \\
\text { E5 }\end{array}$ & $50 \%$ & $\begin{array}{c}\text { "Medalhas do } 1^{\circ} \text { ao } 10^{\circ} \\
\text { [...]Medalhas de } \\
\text { participação para todas as } \\
\text { ginastas não premiadas" }\end{array}$ & regra & $\begin{array}{l}\text { Não } \\
\text { relacionado às } \\
\text { metas }\end{array}$ \\
\hline $\begin{array}{l}\text { c. premiação } \\
\text { percentual - } \\
20 \% 1^{\circ} \\
\text { lugar/ } 30 \% \\
2^{\circ} \text { lugar/ } \\
50 \% 3^{\circ} \\
\text { lugar }\end{array}$ & $\mathrm{E} 1, \mathrm{E} 2$ & $33 \%$ & $\begin{array}{c}\text { "Primeiro lugar - 20\% dos } \\
\text { participantes que atingirem } \\
\text { as notas mais altas - } \\
\text { Segundo lugar - } 30 \% \text { dos } \\
\text { participantes - Terceiro } \\
\text { lugar - os outros } 50 \% \text { dos } \\
\text { participantes" }\end{array}$ & regra & $\begin{array}{l}\text { Criar alto } \\
\text { envolvimento } \\
\text { pessoal }\end{array}$ \\
\hline $\begin{array}{c}\text { d. } \\
\text { premiação } \\
\text { extra } \\
\text { (brindes, } \\
\text { destaques, } \\
\text { etc.) }\end{array}$ & E1, E2 & $33 \%$ & $\begin{array}{c}\text { "Serão realizadas algumas } \\
\text { premiações extras, como: a } \\
\text { ginasta mais simpática, a } \\
\text { mais elegante, a que estiver } \\
\text { vestida com a fantasia mais à } \\
\text { caráter, etc" }\end{array}$ & regra & $\begin{array}{c}\text { Criar alto } \\
\text { envolvimento } \\
\text { pessoal }\end{array}$ \\
\hline
\end{tabular}

Quadro 5 - Ajustes na quantidade e localização dos eventos

\begin{tabular}{|c|c|c|c|c|c|}
\hline $\begin{array}{c}\text { tipos de } \\
\text { ajustes }\end{array}$ & eventos & $\%$ & unidades de significado & $\begin{array}{c}\text { Estratégia - } \\
\text { EC }\end{array}$ & \\
\hline $\begin{array}{l}\text { a. } \\
\text { centralizada } \\
\text { - evento } \\
\text { único anual }\end{array}$ & E3, E5 & $33 \%$ & $\begin{array}{l}\text { *De acordo com calendário } \\
\text { de eventos, estes eventos } \\
\text { foram realizados apenas uma } \\
\text { vez no ano, em uma única } \\
\text { região do estado }\end{array}$ & $\begin{array}{c}\text { Não } \\
\text { relacionado } \\
\text { às estratégias } \\
\text { da EC }\end{array}$ & $\begin{array}{l}\text { Não } \\
\text { relacionado } \\
\text { às metas }\end{array}$ \\
\hline$\frac{\mathrm{b} .}{\text { regionalizada }}$ & E2, E6 & $33 \%$ & $\begin{array}{l}\text { "A regionalização será } \\
\text { realizada em até 06 } \\
\text { competições subdivididas } \\
\text { nas seguintes regiões [...]" }\end{array}$ & $\begin{array}{c}\text { Não } \\
\text { relacionado } \\
\text { às estratégias } \\
\text { da EC }\end{array}$ & $\begin{array}{l}\text { Não } \\
\text { relacionado } \\
\text { às metas }\end{array}$ \\
\hline
\end{tabular}




\begin{tabular}{|c|c|c|c|c|c|}
\hline $\begin{array}{c}\text { c. evento em } \\
\text { etapas }\end{array}$ & $\begin{array}{c}\mathrm{E} 1, \mathrm{E} 2, \\
\mathrm{E} 4\end{array}$ & $50 \%$ & $\begin{array}{c}\text { "a competição será realizada } \\
\text { em duas etapas: } 1 . \\
\text { Individual, } 2 \text {. Conjuntos" }\end{array}$ & $\begin{array}{c}\text { Não } \\
\text { relacionado } \\
\text { às estratégias } \\
\text { da EC }\end{array}$ & $\begin{array}{c}\text { Não } \\
\text { relacionado } \\
\text { às metas }\end{array}$ \\
\hline
\end{tabular}

\section{DISCUSSÃO}

Tomamos como base para a discussão dos resultados os princípios da Engenharia Competitiva, na qual as mudanças sistemáticas que acontecem no ambiente das competições esportivas de jovens atletas buscam promover a motivação intrínseca, melhorando a experiência competitiva (BURTON; GILLHAM; HAMMERMEISTER, 2011). Esses ajustes nas regras do esporte institucionalizado visam desenvolver a paixão pelo esporte, o que ajudará a manter o atleta na prática a partir dos anos de especialização e contribuem para um ambiente competitivo coerente com as diferentes fases da carreira esportiva.

Analisamos também os resultados, a partir do Modelo de Participação Competitiva (LEONARDO; GALATTI; SCAGLIA, 2017), que relaciona o Sistema de Classificação para Programas Esportivos (WIERSMA, 2005) e o Modelo de Desenvolvimento da Participação Desportiva (MDPD) (CÔTÉ; STRACHAN; FRASER-THOMAS, 2008; CÔTÉ; HAY, 2002; CÔTÉ; FRASER-THOMAS, 2007).

Dessa forma, notamos nos regulamentos dos eventos de ginástica rítmica para a categoria mirim, diferentes modificações que objetivam adequar o ambiente competitivo para a faixa-etária em questão. Para uma melhor identificação, a discussão foi subdividida de acordo com as categorias de ajustes encontradas na análise dos regulamentos.

\section{Ajustes na estrutura física e materiais}

No quadro 1 verificamos alterações relacionadas à estrutura física e aos materiais utilizados para a prática da modalidade. Em todos os eventos analisados, houve a supressão total do uso dos aparelhos de GR nessa categoria, trazendo apenas a prova de mãos livres. Essa é uma conduta comum na iniciação, já que, por ser uma modalidade de movimentos extremamente complexos, o domínio dos elementos corporais já é uma tarefa de difícil execução por meninas de sete ou oito anos de idade. Apesar de comum, iniciar o trabalho da GR somente com exercícios a mãos livres para depois de executados corretamente inserir o manuseio de aparelhos, é uma prática metodológica questionável, já que estudos apontam que por meio da prática como um todo - trazida na GR pela interação entre corpo e aparelho - obtêm-se um melhor resultado na aprendizagem do 
que a prática em partes. Além disso, o trabalho do manejo de materiais é altamente motivador para as praticantes e é essencial no início do processo de ensino e aprendizagem (CAÇOLA; LADEWIG, 2008; CAÇOLA, 2007; TIBEAU, 1988).

Se os eventos voltados para a categoria mirim preconizam apenas apresentações sem aparelhos, é lógico supor que grande parte das aulas/treinamentos das equipes participantes serão voltadas para o ensino e treino das habilidades exigidas na competição - mãos livres, em detrimento do trabalho com aparelhos, o que pode em longo prazo prejudicar o desenvolvimento das técnicas de manejo, bem como desmotivar a prática. Uma maneira de estimular o trabalho com aparelhos desde os anos iniciais da prática seria inserir, mesmo que de maneira simples, seu uso nos eventos. Um exemplo são os eventos de participação e diversão sugeridos pelo LTAD do Canadá para crianças de seis a oito anos, como pequenas demonstrações de habilidades, "dia da fita" ou "mini rotinas" (GYMNASTICS CANADA GYMNASTIQUE, 2008), que podem tanto ser um evento em si, ou momentos dentro de eventos maiores.

Nesse caso, aplicar ajustes aos materiais a serem utilizados nesses eventos também seria essencial, para que as crianças se sintam mais confortáveis e consigam realizar os movimentos com maior facilidade. Essa é uma das modificações de equipamentos propostas pela Engenharia Competitiva, que visa atingir a meta de aumentar a ação e pontuação, já que aumentar ou diminuir peso e/ou tamanho dos materiais (bola, fita, arco, por exemplo), pode facilitar a manipulação e permitir a execução correta dos elementos (BURTON, GILLHAM, HAMMERMEISTER, 2011).

Ainda visando alcançar essa mesma meta, verificamos também no quadro 1, que a estrutura física das competições analisadas também foi ajustada para as pequenas ginastas, considerada essa uma das melhores estratégias para aumentar a ação e a pontuação, de acordo com a EC. A maioria dos eventos (66\%) aplica uma redução no espaço da quadra de apresentação. Oficialmente o tablado onde as ginastas se apresentam possui a dimensão de $13 \mathrm{~m}^{2}$. Identificamos nos regulamentos que três eventos utilizam as faixas que compõem o tapete como área de apresentação para cada ginasta aproximadamente $13 \mathrm{mX} 3 \mathrm{~m}$ e um deles mantém o formato quadrado, porém diminuindo para $10 \mathrm{~m}^{2}$. Diminuir o tamanho das quadras pode ser também uma maneira de atingir a meta de estimular maiores pontuações também na ginástica, já que ocupar todo o espaço é um dos quesitos avaliados nos aspectos artísticos (FIG, 2017) e o tablado oficial dificilmente é amplamente utilizado por uma criança pequena, até mesmo pela amplitude que seus movimentos alcançam.

Outro aspecto também relevante presente nos regulamentos, porém com menos frequência, foi com relação à vestimenta das atletas. Oficialmente o código de pontuação da GR prevê uma série de regras para os collants de competição, que em geral são luxuosos, com muitos bordados e texturas e consequentemente de alto custo. Dois eventos sugeriram a utilização de fantasias que 
caracterizem a temática da música da série, o que pode contribuir diretamente para a meta de engajamento prevista na EC de aumentar o envolvimento pessoal, uma vez que o uso das fantasias aproximam a prática esportiva do imaginário infantil, podendo ser um fator motivacional significativo no processo de composição coreográfica, além de estimular o envolvimento da ginasta na criação do exercício, valorizando o aspecto artístico presente na modalidade.

Outro ajuste relacionado à vestimenta foi realizado em apenas um dos eventos encontrados, porém merece destaque: a orientação presente no regulamento é que as ginastas estejam vestidas com os uniformes (de treino) das equipes, o que favorece sobremaneira o estímulo à participação de mais ginastas e equipes iniciantes, já que muitas delas não possuem recursos financeiros suficientes para confeccionar collants de competição para tantas ginastas da iniciação. Reduzir a elitização da prática é oportunizar maior participação para projetos esportivos menos favorecidos financeiramente e consequentemente ampliar o número de praticantes envolvidos nos eventos (LEONARDO; GALLATI; SCAGLIA, 2017).

\section{Ajustes nas regras dos eventos}

No quadro 2 foram elencadas sete modificações de regras relacionadas a aspectos técnicos dos regulamentos. Duas delas estavam presentes em todos os eventos analisados. A primeira diz respeito ao número de apresentações durante o evento. Oficialmente, o código de pontuação de GR prevê a realização de quatro concursos (no individual) para os campeonatos mundiais: CI classificatória; CII - final por equipes; CIII - final individual geral; CIV - final por aparelhos (FIG, 2017). Esse modelo já é alterado até mesmo em eventos oficiais, como por exemplo, os Campeonatos Brasileiros, em que na categoria adulta as ginastas se apresentam apenas duas vezes, em vez de quatro (CBG, 2019). No caso das competições analisadas neste estudo, todas preveem apresentações únicas; isso faz com que o evento se torne menor e, portanto, mais barato e rápido, o que em nível inicial, acaba estimulando a participação, pois há um menor desgaste para as crianças e também maior envolvimento dos pais. Além disso, a própria federação (ou entidade organizadora do evento) consegue reduzir os custos do evento e consequentemente cobrar taxas menores para inscrição, ampliando a possibilidade de mais projetos esportivos participarem.

Com relação aos elementos de dificuldade exigidos para a série de exercícios das ginastas, há uma preocupação geral das federações analisadas em tentar adequar o nível de dificuldade ao nível da competição. Verificamos modificações que limitam os valores máximos e as quantidades de elementos; outras propõem elementos e/ou música obrigatórios e uma delas prevê a execução de séries completas obrigatórias. Essas alterações atuam principalmente no sentido de tentar manter os 
resultados próximos, outra meta de engajamento da Engenharia Competitiva. Tendo valores máximos para a nota de dificuldade, o nível das séries permanece o mesmo, dando ênfase à avaliação da execução; consequentemente as notas finais acabam não ficando tão distantes umas das outras.

Essa proximidade nas pontuações contribui para o estímulo à prática, já que a motivação e o prazer são maiores em competições em que a competitividade e as pontuações são acirradas, devido à sensação de competência ser maior nessas situações. Da mesma forma, quando há maior discrepância, a motivação cai. Atletas que frequentemente se deparam com a derrota com grande margem de diferença para os vitoriosos são sérios candidatos a abandonar o esporte justamente por acreditarem que as perdas refletem sua falta de competência (BURTON, GILLHAM, HAMMERMEISTER, 2011).

Ademais, essa delimitação do nível de dificuldade da série acaba funcionando como uma orientação aos treinadores, sobre quais elementos estão de acordo com a maturidade corporal das ginastas, evitando o ensino precoce de elementos mais complexos ou possíveis lesões.

Outro ajuste de regras identificado foi a diminuição do tempo do exercício. $\mathrm{Na}$ categoria adulta é prevista para a série individual um tempo que varia de um minuto e quinze a um minuto e meio (FIG, 2017). Em dois dos eventos analisados a série para a categoria mirim deverá acontecer com a duração de no máximo um minuto, o que proporciona adequar o número de elementos ao tempo de música, já que para a faixa etária em questão as exigências são menores. Dessa forma também, as crianças terão mais facilidade para decorar as sequências de movimento já que são menores.

Com relação às provas de conjuntos dos regulamentos analisados, uma modificação prevista no evento 1 e no evento 6 é fundamental para ampliar a participação de grupos: permitir a inscrição de grupos de no mínimo duas e no máximo cinco ginastas. Muitas vezes as equipes não possuem a quantidade de ginastas necessárias para formar um conjunto (5 ginastas) e assim deixam de participar dos momentos coletivos dos eventos, que são as apresentações em grupo. Sobre isso, é importante ressaltar que uma das principais orientações para eventos por idade, o FIG Age Group Program (FIG, 2018) prevê para a idade de 7-8 anos, tanto no viés da participação quanto no do desenvolvimento de alto nível, apenas competições em grupos, corroborando a importância do sentimento de pertencimento, uma vez que quando se sentem parte do time, com oportunidade de contribuir significativamente para o sucesso de sua equipe, os atletas se tornam mais autônomos (BURTON, GILLHAM, HAMMERMEISTER, 2011). 


\section{Ajustes no julgamento}

O julgamento das competições de ginástica rítmica é complexo e envolve diferentes quesitos em que as ginastas são avaliadas nos mínimos detalhes. Para imprimir objetividade às avaliações dos árbitros, o código de pontuação da modalidade prevê minuciosamente penalidades para as faltas artísticas e técnicas (pequenas, médias e graves), chegando a deduções de até 1,00 ponto. Porém essa forma de julgar está prevista para o nível técnico de elite, quando as ginastas chegam à categoria principal e competem sob as regras de um evento internacional.

Quando pensamos nas crianças iniciantes comparadas às atletas de elite da categoria adulta, há uma nítida disparidade entre o desenvolvimento e maturidade corporal e a experiência das ginastas menores, que não deveriam ser julgadas da mesma maneira. Nesse sentido, 50\% dos eventos analisados neste estudo propuseram alteração nas faltas técnicas e artísticas, diminuindo os valores das penalidades, o que leva a um julgamento mais coerente com as possibilidades das crianças, que ainda não possuem a maturidade corporal e habilidades necessárias para executar os elementos com a precisão que o código de pontuação exige. Além disso, dois eventos ainda trazem em seus regulamentos a validação da dificuldade corporal, mesmo se houver erros: "a menos que os erros sejam graves a ponto de modificarem a característica do elemento”. Isso pode incentivar a utilização de elementos que ainda não estão sendo perfeitamente executados, mas estão em progressão. Quando não validados, a tendência do treinador é deixar de inserir determinado elemento na série e a ginasta pode deixar de treiná-lo com frequência e não evoluir a ponto de conseguir executá-lo futuramente.

Esses cuidados com o julgamento também estão presentes no Manual da FIG Age Group Program de GR, que prevê a redução das penalidades de execução para as categorias menores (FIG, 2018). Além disso, o próprio código de pontuação também possui uma tolerância para a execução das dificuldades corporais, somente as invalidando em caso de faltas graves, o que já serve de orientação para os demais eventos (FIG, 2017).

Outro ajuste nesta categoria que merece destaque é a redução da quantidade de árbitros. Atualmente para se formar uma banca de arbitragem completa para uma competição de ginástica rítmica, são necessários 10 árbitros no mínimo. Quando consideramos eventos nacionais e internacionais, em que são necessárias duas bancas o número pode chegar a 26 árbitros, levando em consideração o júri superior e juízes de controle (FIG, 2017). Em eventos voltados para a participação e massificação, é necessário reduzir esses custos para que sua realização seja possível. Dois eventos deixam explícito nos regulamentos que a arbitragem será reduzida, juntando critérios de avaliação para um mesmo árbitro: "Cada árbitro irá pontuar a dificuldade e a execução" - no 
caso dos eventos divididos em tiras de tapete, pode-se utilizar um árbitro por espaço, o que reduz pela metade a quantidade necessária, trazendo uma economia considerável para a organização, e consequentemente levando uma baixa demanda financeira aos participantes, características das competições de nível 1 e 2 do Sistema de Classificação para Programas Esportivos, voltados para as categorias de base (WIERSMA, 2005).

\section{Ajustes na forma da premiação}

Verificamos no quadro 4 que todos os eventos analisados preveem ajustes na forma de premiação, quando comparados aos eventos oficiais, em que apenas os três primeiros lugares são premiados. De maneiras diferentes, os seis eventos analisados oferecem medalhas a todas as participantes.

No evento 6 vemos um nível de competição extremamente baixo, já que todas as ginastas são premiadas da mesma forma e não há classificação; o que acontece é um feedback do desempenho por meio da devolução da ficha do exercício arbitrada. Nesse sentido o evento acaba assumindo um caráter de festival ou de demonstração, trazendo um ambiente de menos pressão, apesar de já haver um processo de julgamento e avaliação.

Os eventos 1 e 2 trazem uma forma diferenciada de premiação, em que todas as atletas são premiadas, porém todas são também classificadas em primeiro, segundo ou terceiro lugar. O regulamento prevê que $20 \%$ das notas mais altas obtidas nas apresentações receberão medalha de ouro, $30 \%$ de prata e $50 \%$ de bronze. Essa é uma maneira de incentivar a progressão de uma participação para a outra, ao mesmo tempo em que evita situações constrangedoras de, por exemplo, convidar ao pódio, ao final da cerimônia, as ginastas que não receberam premiação para receber medalha de participação - nessa situação algumas crianças podem se sentir desmotivadas, já que não alcançaram o êxito em receber a premiação pelo mérito de se colocar nos três primeiros lugares do pódio. Os eventos 3, 4 e 5 apesar de ampliarem a premiação até o $6^{\circ}$ ou o $10^{\circ}$ lugar, ainda trazem essa questão à tona.

Uma maneira proposta também pelos eventos 1 e 2 de incentivar aspectos artísticos como criatividade, expressão corporal e facial, postura, entre outros, foi de incluir premiações especiais, entregando brindes às ginastas que se destacarem em alguns quesitos: "ginasta mais simpática, elegante, fantasia mais à caráter, etc”. Essa ação pode, de alguma forma, também estimular as ginastas que se destacam por outros aspectos à prática da modalidade, já que poderão ser reconhecidas para além da avaliação técnica da ginástica aumentando, portanto, seu envolvimento pessoal, já que se sente parte daquele grupo participante. 


\section{Ajustes na quantidade e localização dos eventos}

A oportunidade de participar de eventos esportivos também é considerada uma maneira de estimular a permanência na prática, uma vez que as crianças podem demonstrar o desenvolvimento de suas habilidades aos pais, colegas e também terem um retorno de seu progresso. Assim, percebemos nos eventos analisados que já há, dentro dos limites de cada federação, a intenção de proporcionar mais eventos para as categorias de base. Apesar de essa não ser uma estratégia de implementação da Engenharia Competitiva, não sendo, portanto relacionadas às metas de engajamento, consideramos importante salientar a necessidade de se ampliar o número de eventos, tendo em vista que todos precisam ter acesso às competições, a fim de evitar que haja maiores oportunidades apenas para aqueles que são notados como mais aptos e preparados para competir (LEONARDO; GALATTI; SCAGLIA, 2017).

Dois eventos dos analisados têm sua realização centralizada, sendo realizados apenas uma vez no ano, em uma das regiões do estado. Existem iniciativas para a realização em etapas individual/conjunto; classificatória/final; um evento em cada semestre - e também propostas de regionalização dos eventos, o que leva a ampliação do número de equipes participantes, já que proporciona menor custo com viagens e organização das equipes. Nesse sentido, vemos uma aproximação com as competições de nível 1, em que o compromisso de tempo e dinheiro é mínimo (WIERSMA, 2005).

Em geral, o tipo de alterações percebidas nos regulamentos analisados vai ao encontro da proposta do Sistema de Classificação para Eventos Esportivos, que propõe que para os anos iniciais da prática, os eventos devem ser de nível 1 e no máximo 2, quando a participação é caracterizada por ausência ou níveis relativamente baixos de competição, em que o objetivo é proporcionar a experiência de crianças pequenas e desenvolver entusiasmo pelo esporte em um ambiente não competitivo (nível 1); e desenvolver habilidades e diversão, em vez de focar nos resultados (nível 2) (WIERSMA, 2005).

\section{CONSIDERAÇÕES FINAIS}

Considerando a formação de atleta em longo prazo, voltada para o desenvolvimento positivo de jovens, que priorize nos anos iniciais de prática a participação em eventos como forma de aprendizagem e motivação, os regulamentos dos eventos de ginástica rítmica analisados no presente estudo, foram avaliados tendo em vista as modificações propostas pelas federações para as competições da categoria mirim (7-8 anos). 
Dentre os seis regulamentos analisados, todos fizeram algum tipo de modificação se comparados aos eventos oficiais da categoria principal da modalidade, em diferentes aspectos: estrutura física e de materiais, regras técnicas, julgamento, premiação, quantidade e localização dos eventos. Esses ajustes fizeram com que todos os eventos assumissem características de iniciação e participação, com nível competitivo baixo, se enquadrando nos níveis 1 e 2 de classificação e, portanto, adequados ao nível esportivo a que se propõem.

Dentre as metas de engajamento de atletas propostas pela EC, três delas foram alcançadas nos eventos - aumentar a ação e pontuação, criar alto envolvimento pessoal, manter pontuações próximas. Porém em somente três eventos foram observadas ações que pudessem levar a esses três objetivos simultaneamente. Nos demais eventos, apenas duas das metas foram alcançadas com os ajustes propostos. Ressalta-se que a meta de promover relações sociais positivas nos eventos, não foi identificada em nenhum dos ajustes propostos nos regulamentos analisados, sendo uma possibilidade de ampliação do envolvimento das ginastas participantes da competição.

De maneira geral, os regulamentos das competições analisados no estudo indicam que as federações incluídas na pesquisa demonstram preocupação em trabalhar para adequar os eventos à faixa etária e nível competitivo proposto, oferecendo eventos coerentes à categoria, buscando assim o fomento da modalidade por meio do incentivo à participação e intensificando o processo de massificação, o que pode contribuir para o desenvolvimento futuro de atletas de alto rendimento, assim como para incentivar a vida ativa das participantes ao longo dos anos.

É interessante ressaltar que no caso deste estudo, os regulamentos analisados são de federações estaduais de ginástica, porém competições e festivais com essas características podem ser propostas também pelos próprios clubes, escolas e treinadores de ginástica rítmica, como mais uma possibilidade de participação de suas ginastas em eventos, aumentando a motivação para a prática, bem como a experiência competitiva na modalidade.

Nesse sentido, sugere-se como possíveis encaminhamentos para a elaboração dos regulamentos de competições para as categorias de base na ginástica rítmica: a. Buscar atender às necessidades das idades e níveis técnicos em questão, levando em consideração a premissa de que os eventos voltados para ginastas de iniciação devem assumir um caráter participativo, voltado para a aprendizagem da modalidade e a experiência do "competir", de forma gradual; b. Considerar as Metas de Engajamento do Atleta, assim como as estratégias de implementação propostas pela Engenharia Competitiva, pois as mesmas podem servir de orientação para promover ajustes coerentes e teoricamente fundamentados, buscando aumentar a motivação intrínseca das participantes. 


\section{REFERÊNCIAS}

ARENA, Simone Sagres; BOHME, Maria Tereza Silveira. Federações esportivas e organização de competições para jovens. Revista Brasileira de Ciência e Movimento, v. 12, n. 4, p. 45-50, 2004.

BARDIN, Laurence. Análise de conteúdo. São Paulo: Edições 70, 2011.

BALYI, Istvan. Sport system building and long-term athlete development in British Columbia. Coaches Report, v. 8, n. 1, p. 22-28, 2001.

BENTO, Jorge Olímpio. Pedagogia do desporto: definições, conceitos e orientações. In: TANI, Go.; BENTO, Jorge Olímpio; PETERSEN, Ricardo Demétrio Souza. (Orgs.). Pedagogia do Desporto. Rio de Janeiro: Guanabara Koogan, 2006.

BOMPA, Tudor O. Total training for young champions. Champaign, Human Kinetics, 2000.

BURTON, Damon; GILLHAM, Andrew D; HAMMERMEISTER, Jon. Competitive engineering: Structural climate modifications to enhance youth athletes' competitive experience. International Journal of Sports Science \& Coaching, v. 6, n. 2, p. 201-217, 2011. ISSN 1747-9541.

CAÇOLA, Priscila Martins. A iniciação esportiva na ginástica rítmica. Revista Brasileira de Educação Física, Esporte, Lazer e Dança, v. 2, n. 1, p. 9-15, 2007.

CAÇOLA, Priscila Martins; LADEWIG, Iverson. Comparação entre as práticas em partes e como um todo e a utilização de dicas na aprendizagem de uma habilidade da ginástica rítmica. Revista Brasileira de Ciência e Movimento, v. 15, n. 4, p. 79-86, 2008.

CAFRUNI, Cristina; MARQUES, António; GAYA, Adroaldo. Análise da carreira desportiva de atletas das regiões sul e sudeste do Brasil: Estudo dos resultados desportivos nas etapas de formação. Revista portuguesa de ciências do desporto, v. 6, n. 1, p. 55-64, 2006.

CONFEDERAÇÃO BRASILEIRA DE GINÁSTICA (CBG). Regulamento técnico campeonato brasileiro individual - 2019 - ginástica rítmica. 2019. Disponível em:

https://www.dropbox.com/sh/nr9ptlfltdvt6fo/AAAFEa6AkriRdKICI8oJBq6a?dl=0\&preview=GR 2019 REGULAMENTO CAMPEONATOS+BRASILEIR OS INDIVIDUAL CONJUNTO.pdf . Acesso em: 17/02/2020.

CRANE, Jeff; TEMPLE, Viviene. A systematic review of dropout from organized sport among children and youth. European physical education review, v. 21, n. 1, p. 114-131, 2015.

CÔTÉ, Jean; FRASER-THOMAS, Jessica. Youth involvement in sport. Sport psychology: A Canadian perspective, p. 270-298, 2007.

CÔTÉ, Jean, STRACHAN, Leisha, FRASER-THOMAS, Jessica. Participation, personal development, and performance through youth sport. In: HOLT, N. L. (ed) Positive Youth Development Through Sport. Londres: Routledge, 2008.

CÔTÉ, Jean; HAY, John. Children is Involvement in Sport. Psychological foundations of sport. Boston, MA: Allyn \& Bacon, 2002. 
CÔTÉ, Jean. The influence of the family in the development of talent in sport. The sport psychologist, v. 13, n. 4, p. 395-417, 1999.

FEDERATION INTERNATIONALE DE GYMNASTIQUE (FIG). 2017-2020 Code of Points Rhythmic Gymnastics. 2017. Disponível em:

http://www.gymnastics.sport/publicdir/rules/files/en RG\%20CoP\%202017-

2020\%20with\%20errata\%20Dec.\%202017.pdf. Acesso em: 06/11/2018.

FEDERATION INTERNATIONALE DE GYMNASTIQUE (FIG). Age Group Program. 2018. Disponível em: http://www.gymnastics.sport/site/pages/education-agegroup.php. Acesso em $06 / 11 / 2018$.

GYMNASTICS CANADA GYMNASTIQUE (GCG). Long Term Athlete Development: Gymnastics The Ultimate Human Movement Experience. 2008. Disponível em: http://www.gymcan.org/uploads/gcg ltad en.pdf. Acesso em: 06/11/2018.

GODOY, Arilda Schimidt. Pesquisa qualitativa: tipos fundamentais. Revista de Administração de empresas, v. 35, n. 3, p. 20-29, 1995.

LANES, Bruno Minuzzi et al. Praxiologia motriz: novas proposições para o treinamento dos jogos esportivos coletivos. Motrivivência, Florianópolis, v. 30, n. 54, p. 308-325, jul. 2018. ISSN 21758042. Disponível em: https://periodicos.ufsc.br/index.php/motrivivencia/article/view/21758042.2018v30n54p308/37050. Acesso em: 09 jun. 2020. doi: https://doi.org/10.5007/2175$8042.2018 \mathrm{v} 30 \mathrm{n} 54 \mathrm{p} 308$.

LAW, Madelyn P.; CÔTÉ, Jean; ERICSSON, K. Anders. Characteristics of expert development in rhythmic gymnastics: A retrospective study. International journal of sport and exercise psychology, v. 5, n. 1, p. 82-103, 2007.

LEONARDO, Lucas; SCAGLIA, Alcides José. Oito anos de adaptações competitivas na federação paulista de handebol: um estudo documental da categoria sub-14. Motrivivência, Florianópolis, v. 30, n. 55, p. 75-92, out. 2018. ISSN 2175-8042.

LEONARDO, Lucas; SCAGLIA, Alcides José. Study on youth handball regulations: a documental analysis on the mandatory use of individual defensive system in under -12 and under-14 competitions. J. Phys. Educ., Maringá , v. 29, e2952, 2018 a .

LEONARDO, Lucas; SCAGLIA, Alcides José. A avaliação de competições esportivas de jovens: definição de categorias e aplicações ao handebol. Movimento (ESEFID/UFRGS), v. 24, n. 3, p. 875-888, 2018b.

LEONARDO, Lucas; GALATTI, Larissa Rafaela; SCAGLIA, Alcides José. Disposições preliminares sobre um modelo de participação competitiva para jovens e o papel do treinador. In: GONZALEZ, Ricardo Hugo; MACHADO, Márcia Maria Tavares (orgs). Pedagogia do Esporte: novas tendências. 1ed. Fortaleza; UFC, 2017.

MARCONI, Marina de Andrade; LAKATOS, Eva Maria. Fundamentos da Metodologia Científica. 5 ed. São Paulo; Atlas, 2003. Disponível em: https://docente.ifrn.edu.br/olivianeta/disciplinas/copy of historia-i/historia-ii/china-e-india . Acesso em: 02/03/2020. 
MARQUES, António. Que competições para os jovens desportistas? In: PRISTA, A. et. al. Actividade Física e Deporto: fundamentos e contextos. Porto: FCDEF, 2003. P. 317-321.

MENDES, Felipe Goedert. A trajetória esportiva de atletas de categorias de formação no voleibol brasileiro. Dissertação (mestrado) Programa de Pós-Graduação em Educação Física da Universidade Federal de Santa Catarina. 124f. Florianópolis, SC, 2017.

MENEGALDO, Fernanda Raffi; BORTOLETO, Marco Antonio Coelho. Ginástica para Todos: primeiras reflexões sobre uma prática coletiva. Revista ALESDE, v. 9, n. 4, dez/2018.

MONTAGNER, Paulo Cesar; SCAGLIA, Alcides José. Pedagogia da competição: teoria e proposta de sistematização nas escolas de esportes. In: REVERDITO, Riller Silva; SCAGLIA, Alcides José; MONTAGNER, Paulo Cesar. Pedagogia do esporte: aspectos conceituais da competição e estudos aplicados. São Paulo: Phorte, 2013.

NISTA-PICCOLO, Vilma Leni.; NUNOMURA, Myrian. Os jogos olímpicos na perspectiva da pedagogia do esporte no Brasil. Moreira WW, Bento JO, organizadores. Citius, Altius, Fortius: Brasil, esportes e jogos olímpicos. Belo Horizonte: Casa da Educação Física, p. 171-208, 2014.

NUNOMURA, Myrian; CARRARA, Paulo Daniel Sabino; TSUKAMOTO, Mariana Harumi Cruz. Ginástica artística e especialização precoce: cedo demais para especializar, tarde demais para ser campeão! Revista Brasileira de Educação Física e Esporte, v. 24, n. 3, p. 305-314, 2010.

PARLEBAS, Pierre. Léxico de Praxiologia Motriz juegos, deporte y sociedad. Barcelona, Editorial Paidotribo, 2001.

USA GYM. Chapter three - Competitive Structure. 2019. Disponível em:

https://usagym.org/PDFs/Rhythmic/Rules/2019rp/3 competitionstructure 121919.pdf . Acesso em 02/03/2020.

WIERSMA, Lenny. D. Reformation or reclassification? A proposal of a rating system for youth sport programs. Quest, v. 57, n. 4, p. 376-391, 2005. ISSN 0033-6297.

\section{NOTAS DE AUTOR}

AGRADECIMENTOS - Não se aplica.

CONTRIBUIÇÃO DE AUTORIA - Não se aplica.

FINANCIAMENTO - Não se aplica.

CONSENTIMENTO DE USO DE IMAGEM - Não se aplica.

\section{APROVAÇÃO DE COMITÊ DE ÉTICA EM PESQUISA}

Este estudo faz parte de um projeto de pesquisa maior, aprovado pelo parecer $n^{0} 1.993 .995$ do Comitê de Ética em Pesquisa da Universidade de São Paulo.

CONFLITO DE INTERESSES - Não se aplica. 


\section{LICENÇA DE USO}

Os autores cedem à Motrivivência - ISSN 2175-8042 os direitos exclusivos de primeira publicação, com o trabalho simultaneamente licenciado sob a Licença Creative Commons Attribution Non-Comercial ShareAlike (CC BY-NC SA) 4.0 International. Esta licença permite que terceiros remixem, adaptem e criem a partir do trabalho publicado, desde que para fins não comerciais, atribuindo o devido crédito de autoria e publicação inicial neste periódico desde que adotem a mesma licença, compartilhar igual. Os autores têm autorização para assumir contratos adicionais separadamente, para distribuição não exclusiva da versão do trabalho publicada neste periódico (ex.: publicar em repositório institucional, em site pessoal, publicar uma tradução, ou como capítulo de livro), com reconhecimento de autoria e publicação inicial neste periódico, desde que para fins não comerciais e compartilhar com a mesma licença.

\section{PUBLISHER}

Universidade Federal de Santa Catarina. Programa de Pós-Graduação em Educação Física. LaboMídia - Laboratório e Observatório da Mídia Esportiva. Publicado no Portal de Periódicos UFSC. As ideias expressadas neste artigo são de responsabilidade de seus autores, não representando, necessariamente, a opinião dos editores ou da universidade.

\section{EDITORES}

Mauricio Roberto da Silva, Giovani De Lorenzi Pires, Rogério Santos Pereira.

\section{HISTÓRICO}

Recebido em: 10 de março de 2020

Aprovado em: 19 de junho de 2020 